\title{
A new approach to flood vulnerability assessment for historic buildings in England
}

\author{
V. Stephenson and D. D'Ayala \\ Civil, Environmental and Geomatic Engineering, University College London, London, UK \\ Correspondence to: V. Stephenson (victoria.stephenson.12@ucl.ac.uk)
}

Received: 27 August 2013 - Published in Nat. Hazards Earth Syst. Sci. Discuss.: 31 October 2013

Revised: 26 February 2014 - Accepted: 7 March 2014 - Published: 5 May 2014

\begin{abstract}
The recent increase in frequency and severity of flooding in the UK has led to a shift in the perception of risk associated with flood hazards. This has extended to the conservation community, and the risks posed to historic structures that suffer from flooding are particularly concerning for those charged with preserving and maintaining such buildings. In order to fully appraise the risks in a manner appropriate to the complex issue of preservation, a new methodology is presented here that studies the nature of the vulnerability of such structures, and places it in the context of risk assessment, accounting for the vulnerable object and the subsequent exposure of that object to flood hazards. The testing of the methodology is carried out using three urban case studies and the results of the survey analysis provide guidance on the development of fragility curves for historic structures exposed to flooding. This occurs through appraisal of vulnerability indicators related to building form, structural and fabric integrity, and preservation of architectural and archaeological values. Key findings of the work include determining the applicability of these indicators to fragility analysis, and the determination of the relative vulnerability of the three case study sites.
\end{abstract}

\section{Introduction}

In recent years numerous extreme precipitation events and subsequent flood events have occurred in the UK. In November 2009, when flooding affected numerous towns in Cumbria, a record $314 \mathrm{~mm}$ of rainfall fell in $24 \mathrm{~h}$. Provisional analysis suggests that such an event has a return period of over $300 \mathrm{yr}$ (Hannaford, 2009), whilst an extreme rainfall event contributing $145 \mathrm{~mm}$ of rain falling in $25 \mathrm{~h}$ at Pershore,
Gloucestershire in July 2007 was associated with a return period in excess of $1000 \mathrm{yr}$ (NERC, 2007). Very recent flooding and extreme rainfall events, such as that which caused flooding in Tewkesbury in May 2012 (Fig. 1) and the falling of $89 \mathrm{~mm}$ of rainfall in a single day in Keswick, Cumbria in June 2012 (Met Office, 2012), or the floods in York in autumn 2011 and 2012 (York Press, 2012) demonstrate the continued presence of this threat. In light of the potential changes to precipitation conditions projected for the UK for the future, where rainfall is expected to become more intense and seasonal in nature (Osborn and Maraun, 2008), flood hazard is likely to cause further increase in the severity and spread of associated damage, if mitigation measures are not implemented.

The widespread inundation of Southern England in the winter of 2000/01, the most severe nationwide flood episode since the snowmelt of 1947 (NERC, 2000), and the widespread flooding of Gloucestershire and Worcestershire in 2007 (Marsh and Hannaford, 2007), have impacted upon large numbers of UK historic structures and increasing concern has been voiced on risks posed by flood events to historic buildings, due to varied weather patterns (Cassar, 2005; Sabbioni et al., 2006). In Europe a similar trend has been observed, with especially severe flooding occurring on the continent in 2002 (Ulbrich et al., 2003), heightening the perception of risk and culminating in a multitude of studies into flood risk mitigation (Genovese, 2006; Theiken et al., 2005; Petrow et al., 2006)

These concerns demonstrate a need for flood risk appraisal to become a more integrated and developed component of conservation management, with the successful preservation of our built cultural heritage requiring greater depth of 


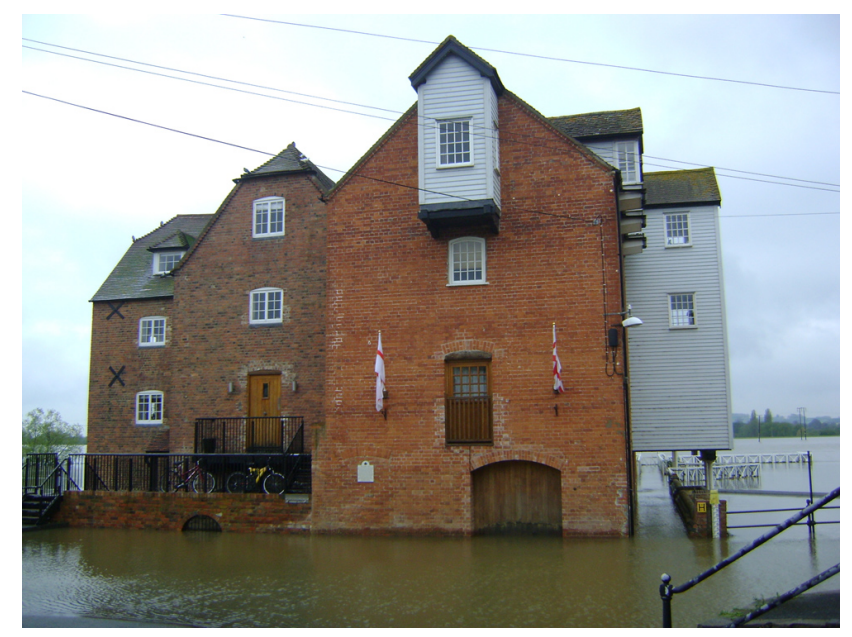

Fig. 1. Recent flooding at Tewkesbury (Stephenson, 2012).

understanding of the vulnerability of historic structures to flood inundation, and associated extreme rainfall events.

Traditionally flood hazard mitigation practices have taken a preventative approach, where design standards for flood defences are derived from the control of flood water based upon probability of event occurrence, or return period (Smith and Ward, 1998; FEH, 1999; MAFF, 1993). In recent years focus has shifted away from this control approach, to one that looks at the problem from the wider perspective of flood risk (Evans et al., 2006; Merz et al., 2010a), with authorities being made responsible for taking a broader consideration of the methods of mitigating flood impact (DEFRA, 2011). One key implication of this is that much greater focus is placed upon the consideration of physical losses caused by flood damage to assets such as buildings and infrastructure systems (Merz et al., 2010b).

This approach determines that inherent resilience of those assets must be identified, or in other words the vulnerability of the assets to the flood hazard. This provides information that contributes to the allocation of resources to mitigate the impact of flood events over geographical and economic districts.

Damage assessment is typically discussed in terms of both direct and indirect damage, and can also be tangible and intangible (Messner et al., 2006; Smith and Ward, 1998; Merz et al., 2010a). As regards the study of historic buildings at the micro-scale assessment level, the direct tangible damage is the physical damage caused to the building fabric. This can be particularly severe, as historic structures are most commonly composed of absorbent building materials, often compromised by age and condition, which are susceptible to decay and damage as a result of moisture ingress. In addition the irreplaceable loss of cultural heritage represents a direct intangible damage, and any loss of revenue from tourism due to repair works and closures during the post-flood recovery is a further indirect, tangible damage. For the purpose of this paper only measures of vulnerability that contribute to direct tangible and direct intangible damage are considered.

Damage models are used widely as the fundamental tool in estimating flood loss. There are a large number of different models used within the flood risk management community, for which the structure, inputs and outputs are determined by the purpose of the model (Jongman et al., 2012). The large range of applications covering varying spatial scales, regional zones and asset typologies has led to divergence of methods to an extent; however, depth-damage functions remain the internationally accepted means of assessing direct physical damage (Thieken et al., 2005). The function measures loss through the direct monetary damage caused, and relates this to the depth of flood.

In the case of building assets these functions are largely organized by classification of building use (Penning-Rowsell et al., 2005; Elmer et al., 2010; Kelman, 2002), with damage caused to a specific type of building narrowing and focussing the scope of the function. Different flood parameters are sometimes considered (Messner et al., 2006; Kreibich et al., 2009, Nadal et al., 2010, Elmer et al., 2010), although flood depth dominates the range of functions available.

Historically these functions have not generally accounted for characteristics of the building other than through their contribution to economic worth, although in recent years this trend has begun to change. Recent assessments often include assessment of structural characteristics (Maiwald and Schwarz, 2012; Mebarki et al., 2012; Kelman and Spence, 2003), and these approaches are beginning to determine that a more accurate and detailed assessment of flood loss is achieved. Probabilistic approaches to the structural assessment are also beginning to emerge, reflecting the approach taken in seismic vulnerability assessment (D'Ayala et al., 2006).

However, there remains in the body of literature a lack of flood loss estimation methods that account for the highly specialised nature of historic buildings' vulnerability to flooding. There has been a proactive approach to monitoring and measuring flood damages to historic buildings in recent years (CHEF, 2011, NOAH'S ARK, 2004) largely driven by the large number of catastrophic floods that have occurred in Europe in the last decade affecting major world heritage sites. The work has however remained descriptive in nature (Drdacky, 2010; English Heritage, 2004), with consideration of losses other than physical building damage often also a dominating feature of the damage assessment (Holicky and Sykora, 2010a, b).

Whilst it is possible to partially assess the loss caused to a historic building with a more widely applicable approach, there are a number of factors that contribute to the need for a specifically derived method and the associated damage function. Economic assessments do not account for the loss of intangible and irreplaceable historic building fabric, whilst purely engineering and structurally based methods 
will potentially overestimate the resilience of the buildings, in that no account of material condition is incorporated.

Furthermore, singular use of the parameter flood depth does not represent accurately the nature of the hazard posed to historic buildings by flood. Absorbency of the fabric determines that flood duration is equally significant in contributing to damage, as is flood velocity, which poses a threat to the delicate, organic materials common to historic buildings.

A more suitable approach is one that takes a holistic view of the nature of the historic building as an asset, and looks to determine vulnerability based upon a range of factors that contribute to the overall social and economic value it represents, and its true interaction with the flood water. From this assessment the relative vulnerability of stock within an urban historic site can be undertaken and appropriate mitigation measures implemented.

This paper presents a methodology for such a holistic approach, bringing together data that characterises the intrinsic properties of the building that contribute to its vulnerability to flood inundation. Demonstration of the method through three urban case studies shows that these characteristics are able to profile the relative vulnerability of differing historic building typologies and sites, in order to determine the loss they will potentially experience. Mapping of this vulnerability within the flood hazard extent provides information critical to the sites' flood risk management.

\section{Loss estimation: cultural value and intrinsic vulnerability}

The rationale for the estimation of damage is to determine the potential for loss present in each individual building, based upon a number of intrinsic characteristics. Typically used flood depth-damage curves are either derived from damage data collected following a flood event (Schwarz and Maiwald, 2008), or through expert judgement of the relationship between flood severity and asset damage. Anecdotal information regarding the damage caused to historic buildings by floods is scarce. Nor is it organised into any systematic database that could form the basis of a damage function derived from observed effects.

It is hence proposed to derive and test a synthetic vulnerability function based partly on the expected response of the building, which is informed upon by engineering judgement and diagnosis, and partly from the perceived economic and historic value the building has. In the light of a lack of anecdotal evidence of damage from previous flood events this approach represents the most comprehensive loss estimation technique available. As more damage data is collected, review of the parameters will be possible, providing for derivation of a more empirical function.

The scope of the assessment is for the current time limited to the study of residential and small commercial buildings. This is in accordance with much of the other work investi- gating the relationship between flood parameters and damage to buildings (Kelman, 2002; Maiwald and Schwarz, 2012). It allows for a more detailed assessment of the assets, as it limits the number of parameters considered to those applicable to individual building typologies.

The study of the historic buildings in this survey focused upon measurement of seven descriptive parameters (Table 1):

- age,

- listed status,

- use,

- footprint,

- number of storeys,

- materials and structure,

- condition.

The listing of a building in the UK represents a formal acknowledgement of the historic value of the structure, and is designed to ensure that the heritage it encompasses is safeguarded. Once listed a structure will be placed on The National Heritage List, which serves as a ledger of all recognised heritage, used for planning guidance. This is maintained by English Heritage, the governmental body responsible for preserving the UK's heritage. Listing incorporates three grades, each designed to recognise an increasing level of value, and hence each is associated with stricter rules as regards the use and management of the structure. The grades are Grade II, Grade II* and Grade I, with Grade I signifying the highest possible level of value (English Heritage, 2012), and hence contributing the smallest proportion to the listed building stock. Although not explicitly the case, each of the listing stages can also be translated into structures of international (Grade I), national (Grade II*) and regional (Grade II) importance.

Age and listed status combined therefore provide a measure of the value of the cultural asset, whilst use measures its revenue potential. The footprint of the building and its number of storeys provide the metrics of the asset at risk. The materials and structural system relate to the susceptibility of the building fabric to be damaged by flood, whilst the condition of the building is a measure of the resilience of the structure to the stresses placed upon it by the hazard.

For each parameter a range of attributes varying between 3 and 5 was determined through logical derivation of the maximum possible number of responses and these were assigned a vulnerability rating (VR) on a scale from 10 to 100 . The scale is divided into equal, unweighted parts according to the number of attributes, with that indicating lowest vulnerability assigned the value 10 , and that indicating the highest assigned the value 100 (Table 1). No attribute has been assigned the value 0 on the scale, since it is considered that 
Table 1. Vulnerability descriptor ratings.

\begin{tabular}{llr}
\hline Descriptor & Response & VR \\
\hline Age & Medieval/Tudor & 100 \\
& Jacobean & 77.5 \\
& Georgian & 55 \\
& Victorian & 32.5 \\
& Modern & 10 \\
\hline Listed status & Grade I & 100 \\
& Grade II* & 70 \\
& Grade II & 40 \\
& Not listed & 10 \\
\hline Storeys & 4 & 100 \\
& 3 & 70 \\
& 2 & 40 \\
& 1 & 10 \\
\hline Construction & Earth & 100 \\
& Timber frame & 70 \\
& Brick masonry & 40 \\
& Stone masonry & 10 \\
\hline Condition & Poor & 100 \\
& Good & 55 \\
& Excellent & 10 \\
\hline
\end{tabular}

every historic building feature measured indicates some degree of vulnerability to the hazard; however, in order that all of the descriptors contribute equally a lower boundary of 10 is applied to the rating scale for all descriptors.

The ranking of the attributes within each descriptor takes into account that the vulnerability is a function of the nature of the specific hazard considered. By way of an example, if the hazard freeze-thaw were being studied, limestone masonry, which suffers particularly high levels of damage due to exposure to freeze-thaw action, would be considered more vulnerable than timber framing. Conversely, if flood loading is being analysed, the presence of a shop front renders a building more vulnerable, as the glass will be more prone to failure than a solid wall.

The rationale for the ranking for each parameter in this assessment is:

- Older buildings, and those with higher listing classification, present a more valuable asset and are therefore of higher vulnerability.

- In the presence of superficial foundations a building with more storeys over the same footprint will be more susceptible to the stress differentials generated by saturation and drying of the foundation soil during and after a flood.

- Lateral capacity of wall structure, combined with absorption capacity of building materials indicates stone masonry to be the least vulnerable, and timber-frame and earth facades to be most.

- Buildings in overall poorer condition, with less evidence of a continued programme of repair and maintenance, will be more vulnerable to inundation due to pre-existing fatigue in the structure and fabric. Consideration of both the state of repair of the original fabric and the quality of any intervention work is included.

Initial assessment of the data focuses upon each parameter individually, analysing the variation of parameter responses for each of the buildings, and the contribution this makes to the relative vulnerability of the building stock by typology and across the sites. Development of the method combines the parameters to contribute to an overall vulnerability index (VI) assigned to a given building. The lack of empirical damage data currently prevents the VI, and buildings associated with a given VI value, from being directly related to the hazard, through either flood depth or duration. Rather, the rating allows for each asset to be considered relative to other assets at the same or other sites using a single descriptor, irrespective of hazard and exposure.

The final stage in the assessment collects the VI values for all of the buildings on a given site together to determine the cumulative site VI, which ultimately aids in efficient management of countrywide risks and allocation of national resources during the flood risk appraisal process. This approach has been tested through application to three case studies as discussed in the following section.

\section{Case studies}

The sites chosen are Tewkesbury in Gloucestershire (southwestern England), York in North Yorkshire (northeastern England) and Winchester in Hampshire (southeastern England). Each of the sites presents an urban concentration of a wide range of historic building types, covering a long historical period, and incorporating a multitude of building materials and construction methods. Furthermore, each of the sites accommodates a major river system, in close proximity to the estuary, with a large catchment area, representative of many of the major river catchments in the UK. However, none of the sites is situated in high precipitation areas for the UK, according to current annual averages for the UK (Fig. 2). The three sites are briefly described and compared in terms of hazard assessment in the following paragraphs.

The town of Tewkesbury is located in the county of Gloucestershire, southwestern England, on the River Severn. The historic origins of the town lie in the monastic settlement that grew on the site prior to the Norman conquests. Today much of the town's historic building stock has survived in good condition, and Tewkesbury is often revered for its timber-framed structures, and also for the 12th century abbey, which dominates the skyline. The town sits within the 


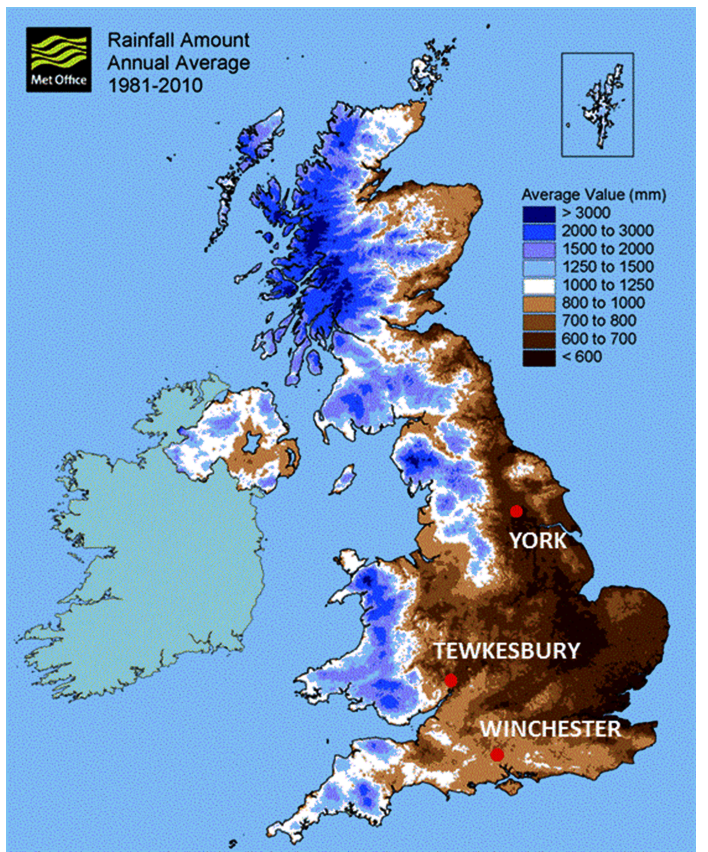

Fig. 2. Annual average precipitation map of the UK showing location of three case study sites.

vast flood plain of the River Severn at an altitude of approximately $40 \mathrm{~m}$ above mean sea level, and is exposed to the weather systems that move up the Severn Estuary and bring the town much of its rainfall. Tewkesbury does have a history of recorded flooding dating back to the 16th century, with the floods of 1947 being particularly severe. In more recent times the extensive flooding of July 2007 caused severe damage to large numbers of historic properties in the town. Since 2007 Tewkesbury has also flooded multiple times (Fig. 1).

The city of Winchester sits within the flood plain of the River Itchen, which has its mouth south of the city in Southampton. Winchester has experienced numerous periods of growth throughout its long and distinguished history, providing today a rich and varied stock of historic structures ranging in age from the medieval St. John's House, through the numerous 14th century buildings of Winchester College to the Victorian Guildhall. Added to this the monumental Winchester Cathedral, built in the 11th century, is a prominent feature in the historic building stock, which also suffers from annually recurring flooding inside the crypt. Aside from recurrent normal flooding the whole city suffered badly when in the autumn periods of 2000 and 2001 widespread flooding occurred across the south and east of England.

Of the three case study sites, York (Fig. 3) is historically most prone to flooding, with the earliest detailed account of a flood event occurring in 1263 (MacDonald, 2011), and the most recent flooding taking place in 2012. The highest recorded flood inundation occurred in autumn 2000, although occurrences where the River Ouse, which runs

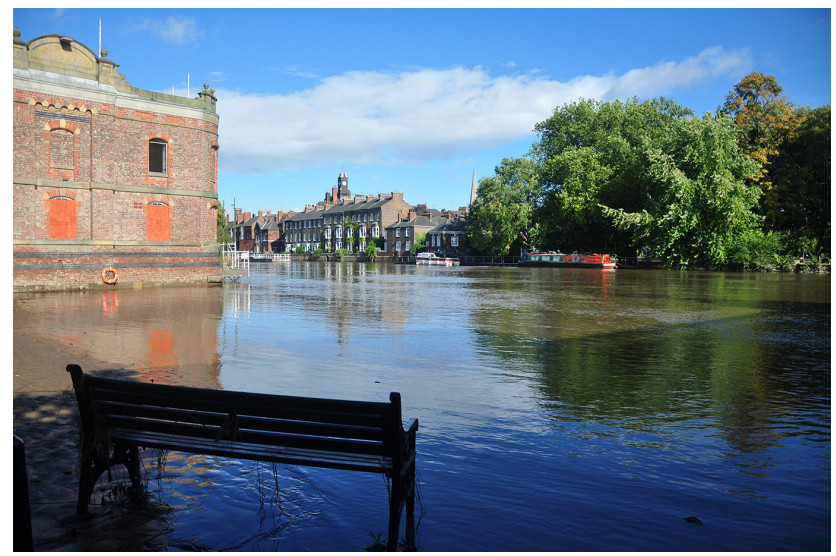

Fig. 3. Recent flood events at York (2012, Photo courtesy of Y. Didem Aktas).

through the centre of the city, floods its banks are common at an almost annual frequency. The historic building stock in York is widely variable and noticeable periods of growth can be observed through analysis of historic maps of the city. The earliest portions of the city date from Roman times, when the city was founded, whilst the medieval growth of the town is still evident through the large numbers of timber framed structures in the centre of the city, and there is also a strong Georgian architectural influence.

\section{Site vulnerability assessment}

To characterise the vulnerability of the buildings and sites, data collection was carried out at three different scales: the whole city, at street level and at building level. This allowed for focus on specific critical parameters at each scale. Prior to visiting each site, a desktop study of the Environment Agency flood risk maps (EA, 2010) was conducted to determine the areas of the city centres most at risk of flooding, so as to concentrate the building survey on these portions of the sites. This defined the extent of each sample. From this sample key buildings were chosen for detailed inspection, selected to provide a representative cross section of building typologies and distribution within the stock. Analysis was also carried out on the percentage of the total historic building stock that was within the flood risk area, to inform judgement of the risks at the site as a whole. Visits were made to each of the sites during 2010 and 2011 and in total between 100 and 200 buildings were surveyed at each of the three sites.

Table 1 summarises the descriptors and vulnerability ratings for each of the parameters considered at this stage. The parameter use and footprint do not contribute at this time, due to lack of available data. For each building surveyed a single photograph of the principal façade was taken, to provide a visual database reference in case of any need for future 

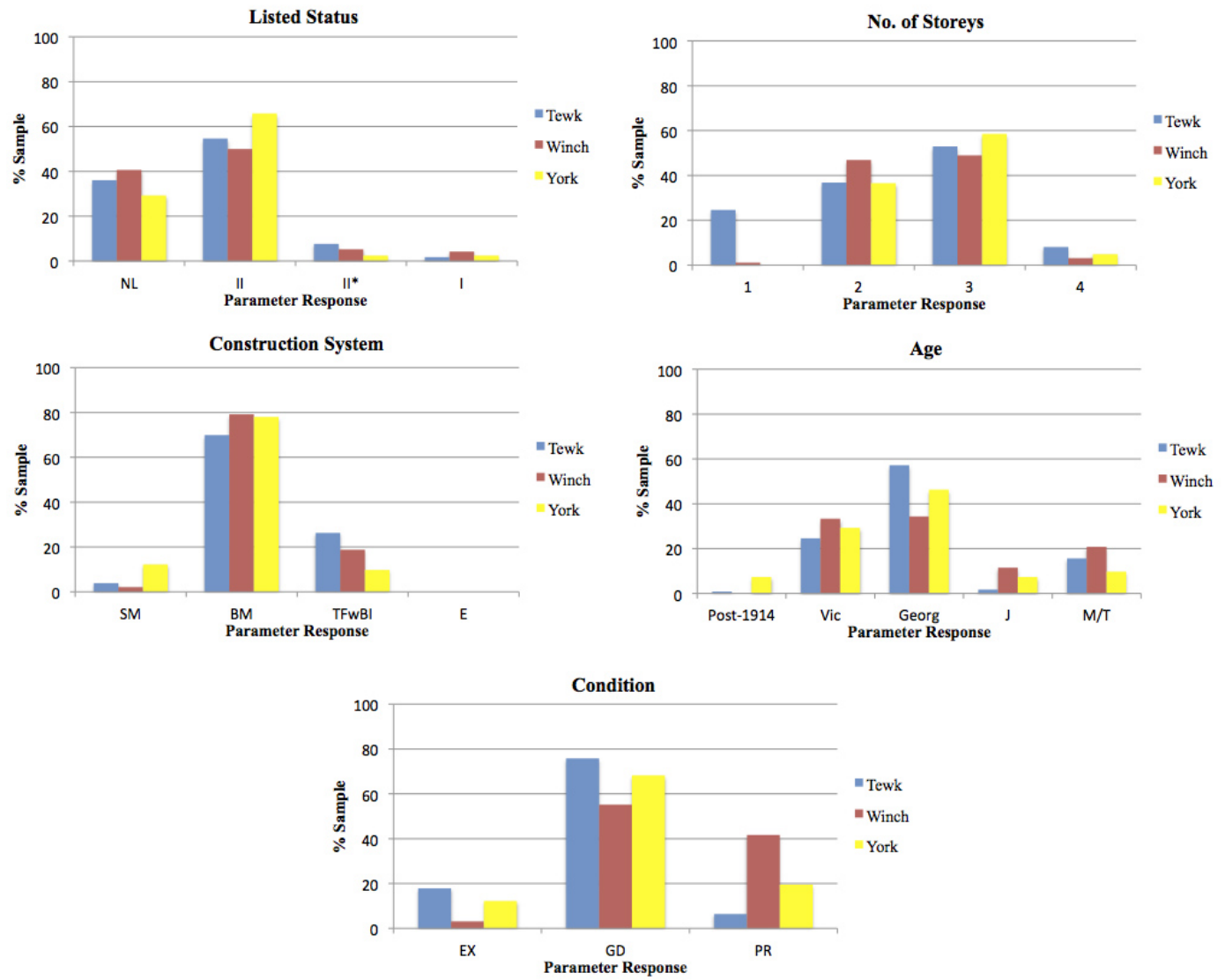

Fig. 4. Distribution of vulnerability parameter responses for three sites: Tewkesbury, Winchester and York.

work, together with hand sketches depicting specific features related to fabric condition and position of openings.

The sample data set that has been produced through the site survey is a discrete data set focussing exclusively on the historic buildings ${ }^{1}$ contained within the urban stock at each of the sites. Any statistical inferences that are therefore made apply only to the historic stock and the vulnerability of those building typologies. Site-wide generalisations about flood risk are not the aim of the analysis of the data.

Studying the data across the whole sample for each parameter demonstrates the spread of vulnerability across the building stock at the sites (Fig. 4). Initial assessment of the data collected showed that generally the sites differ significantly, dependent upon which parameter is being considered. The Tewkesbury sample is seen to have a generally older building stock in the hazardous area than the other sites (Fig. 6a and b), with the highest proportion of timber framed structures and very few unlisted buildings. In comparison the Winchester sample comprises a much larger percentage of brick masonry buildings (Fig. 7a and b), which are generally

\footnotetext{
${ }^{1}$ For the purposes of this survey "historic" refers to any building built before the mainstream use of concrete and steel in domestic construction. This is estimated to be a building produced before the First World War, i.e. pre-1914.
}

younger in age and more likely to be unlisted. York is similar to Winchester in that brick masonry comprises the majority of the sample; however, a slightly smaller proportion of the sample is listed (Fig. 8a and b).

Due to the relatively small number of descriptor responses the data is more readily analysed if it is considered as discrete. In the raw cumulative distribution the limited number of data points determines that accurate interpolation between the values of VR is not easily determined. Future iterations of the method will determine more numeric means of measuring each of the descriptors, such as ratio of solid wall to window, or storey height to full building height. This will generate a more continuous data set, which will in turn better fit a cumulative distribution.

A cumulative log-normal distribution function of the vulnerability ratings for each descriptor has been derived at this stage to determine the fit, shown in Fig. 5, where the raw cumulative data points are also shown. The curves are shown comparatively for each of the sites, and each fan of curves demonstrates the relative vulnerability of each site within the whole sample. The fans show a mixed degree of relative vulnerability between the sites, with each of the three locations providing the upper or lower boundary for one or more 
descriptor fan. In addition, each of the descriptors produces a fan of curves of slightly differing shape.

Whilst the descriptors age, number of storeys and construction system tend towards displaying typical curves attributed to a normally distributed data set, the remaining two descriptors produce curves with less standardised distribution functions. This is to a certain extent to be expected, as relatively uniform age and construction typology are what make an historic centre characteristic and appealing. The listed status curve is skewed towards the lower vulnerability end, which is unsurprising considering that the vast majority of listed structures are classified Grade II, with only a very small proportion Grade II* or Grade I. The condition curve is limited by the descriptor being segmented into only three possible responses, and improved resolution of the grading system for condition is acknowledged as key to future development of the method.

The fit of the log-normal distribution to the raw data is generally quite good in terms of the shape, although the distribution underestimates the vulnerability of each of the samples for all the descriptors, at each level of increasing vulnerability including at the uppermost level $(\mathrm{VR}=100)$, where $f(x)=1$ is not reached. It remains the case however that due to the discrete nature of the data, fitting such a curve is key to demonstrating the applicability of the method to fragility analysis.

These curves, which follow the expected shape of curves generated by fragility analysis of engineered structures (D'Ayala, 2005), are a positive indication about the suitability of using these descriptors for vulnerability analysis, as these are applied when studying the vulnerability of buildings to damage through exposure to naturally occurring environmental hazards, such as earthquakes, volcanoes, and floods. These curves therefore allow for accurate comparison of different sites at different vulnerability thresholds on the same scale. This means that a more accurate evaluation of the relative vulnerability of each stock group, and the individual buildings within the stock, can be determined relative to the general UK historic building field. This in turn will promote more informed allocation of resources to mitigate the risks.

The weighting of vulnerability ratings in a non-linear manner will improve the fit of the data to common fragility analysis. However, there is no precedential work to suggest suitable weightings for these descriptors in relation to the flooding hazard. This leads to a focus on other influences that may inform the design of weighting, including structural engineering concepts and archaeological guidance, which would apply the method at a national level. In the case of the listed status of the buildings, English Heritage guidance on the proportion of listed buildings assigned to each grade states that $92 \%$ of all listed structures are Grade II, with only $5.5 \%$ Grade II* and $2.5 \%$ Grade I (English Heritage, 2012). This would provide a clear distribution of weightings of relative vulnerability for those buildings listed. However, the inclusion of non-listed buildings in the current survey highlights the fact that a large degree of modification would be required in order to apply this across multiple sites.

There is some further iteration of the indicators needed, which will develop as a result of analysis of anecdotal damage data. An increased number of storeys for example could be used to indicate increasing or decreasing vulnerability. A larger building, with a higher number of storeys or of a larger footprint, will weigh more and hence provide more resistance to buoyancy. Additionally, more storeys would increase the vertical load applied at ground floor level, which in turn provides greater resistance to lateral loading from differential flood depths. This opinion is supported by the international literature, where an increased number of storeys does indicate higher resilience when flood hazard is considered as a combination of flood depth and velocity (USACE, 1985; HAZUS, 2009).

At this stage however it is felt that the rationale set out in Sect. 2, whereby increased storeys equate to increased stress at foundation level and subsequently more potential for settlement, is the correct application of this indicator at this time. The generally slow rates of water rise and flow velocity seen in overland UK flooding reduce the risk of buoyancyrelated damage, whilst flood water generally rises at equal height inside and outside of buildings in this case, which reduces the likelihood of large lateral forces developing.

Furthermore, the building materials present in these structures are particularly susceptible to damage during the period after the flood water has receded, when drying and hence shrinkage occurs. As more anecdotal evidence of flood damage is collected this rationale may be subject to change, given consideration of local ground conditions such as substrata and history of pre-load, although to date existing anecdotal evidence suggests that there is a high resilience to flood velocity-related damage, in that very few buildings are ever carried away by floodwater in the UK.

Of equal concern is the consideration of building condition, and the development of an accurate and objective method of assessing this. For the survey data presented here a simple, three-stage grading scale has been used, and it is felt that this is appropriate for this first attempt at measuring vulnerability. However, the approach to diagnosis and condition assessment of historic buildings is a multi-faceted one, which remains fundamentally subjective and much influenced by the personal experience of the surveyor or engineer involved. Improvement of the means of assessing the condition of the building and its influence on vulnerability is a key concern for the development of this method in the future, although it is felt that this is currently beyond the scope of this initial multi-parameter assessment.

In such a type of assessment it is important to ascertain that the parameters chosen are independent of each other and measure different facets of the vulnerability function. Whilst the cultural, historic and architectural value of the building is typically recognised and measured through any listing of the building (English Heritage, 2012), age is known to be 

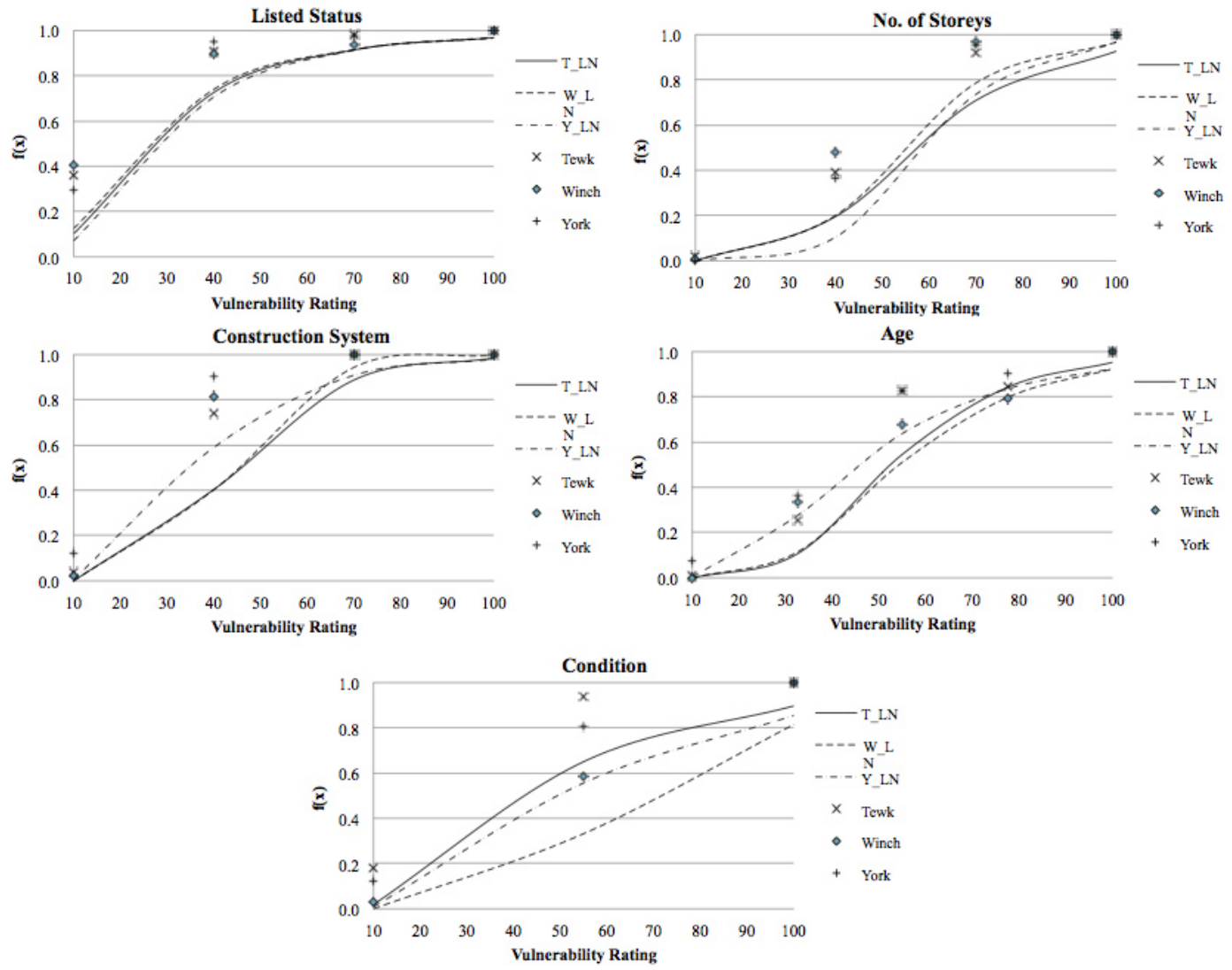

Fig. 5. Vulnerability descriptor log-normal and raw cumulative distribution for three sites: Tewkesbury, Winchester and York.

the most influential contributor to the listing of a structure. However, it is also the case that many historic structures are unlisted for no reason other than their lack of proposal to the regulatory bodies. Additional complications arise from such factors as different areas of the country's historic building stock being listed more comprehensively, accurately and conscientiously than others. Conversely the relationship between condition and listing is explicitly non-contributory, as stated in the governmental guidance on the selection of listing buildings (DCMS, 2010). This suggests that the two factors should remain as separate indicators of vulnerability.

Furthermore, whilst it is true that the development and improvement of certain building materials and technologies over time is reflected in their prevalent use in structures, architectural and aesthetic fashions also play a key role in the fluctuations of use of materials over time. Moreover, a covariance analysis has shown generally low levels of correlation across the data sets collected, demonstrating the independence of each of the descriptors used in the vulnerability assessment for these three sites.

To demonstrate the impact of the method on the assessment of vulnerability, a selection of six buildings is shown below. These are three pairs of buildings from each of the sites (Tables 2-4 and Figs. 6-8), which by a typical clas-
Table 2. Tewkesbury vulnerability index comparison.

\begin{tabular}{ll}
\hline \multicolumn{2}{l}{ Barton Street, Tewkesbury } \\
\hline Not listed & 10 \\
3 storeys & 70 \\
Timber frame with BI & 70 \\
Georgian & 55 \\
Excellent condition & 10 \\
Vulnerability index & $215 / 500$ \\
\hline Mill Bank, Tewkesbury \\
\hline Grade II & 40 \\
3 storeys & 70 \\
Timber frame with BI & 70 \\
Medieval/Tudor & 100 \\
Excellent condition & 10 \\
Vulnerability index & $290 / 500$ \\
\hline Case 1: timber-frame residential buildings in \\
Tewkesbury.
\end{tabular}

sification of use or building material might be considered equally resilient to a flood. However appraisal with the method proposed shows the divergence in their overall vulnerability when considered as historic assets. 

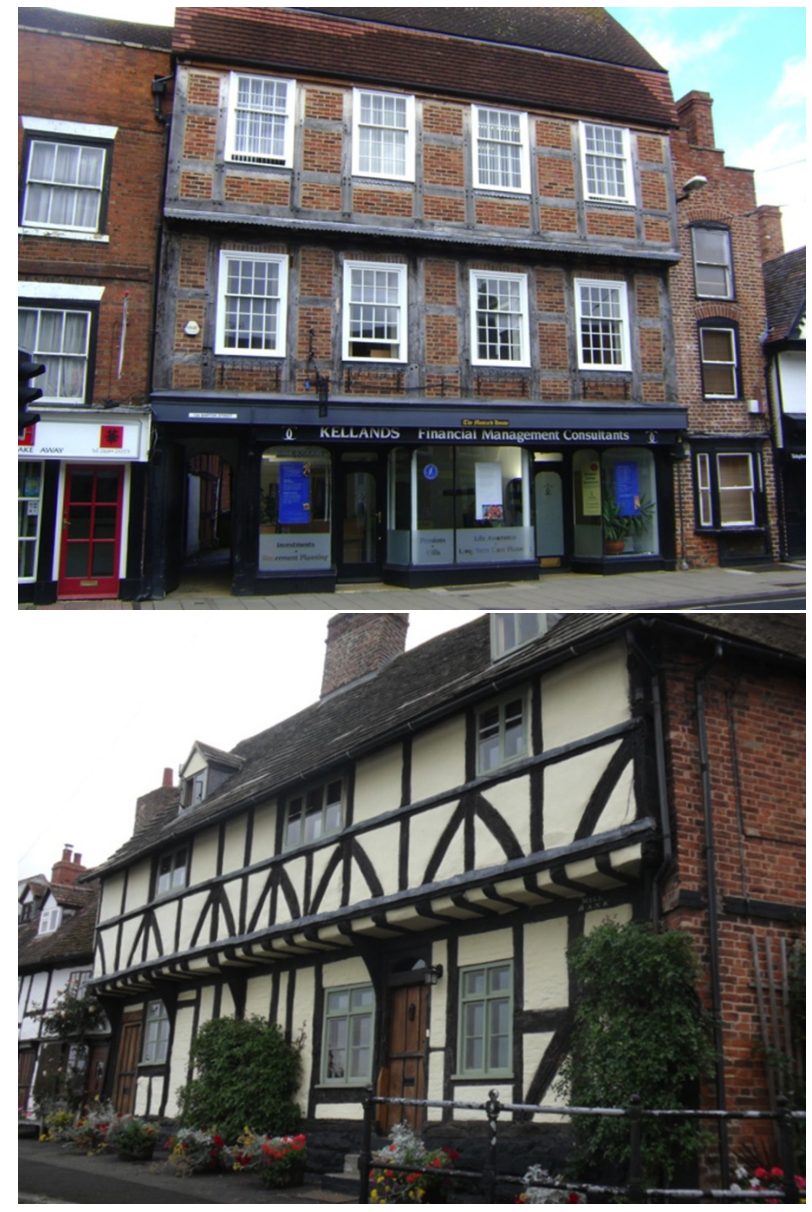

Fig. 6. (a) Barton Street, Tewkesbury, (b) Mill Bank, Tewkesbury.

Table 3. Winchester vulnerability index comparison.

\begin{tabular}{ll}
\hline \multicolumn{2}{l}{ Water Lane, Winchester } \\
\hline Not listed & 10 \\
2 storeys & 40 \\
Brick masonry & 40 \\
Victorian & 32.5 \\
Good condition & 55 \\
Vulnerability index & $177.5 / 500$ \\
\hline Kingsgate Street, Winchester \\
\hline Grade II & 40 \\
3 storeys & 70 \\
Brick masonry & 40 \\
Jacobean & 77.5 \\
Poor condition & 100 \\
Vulnerability index & $327.5 / 500$ \\
\hline
\end{tabular}

Case 2: brick masonry residential buildings in Winchester.
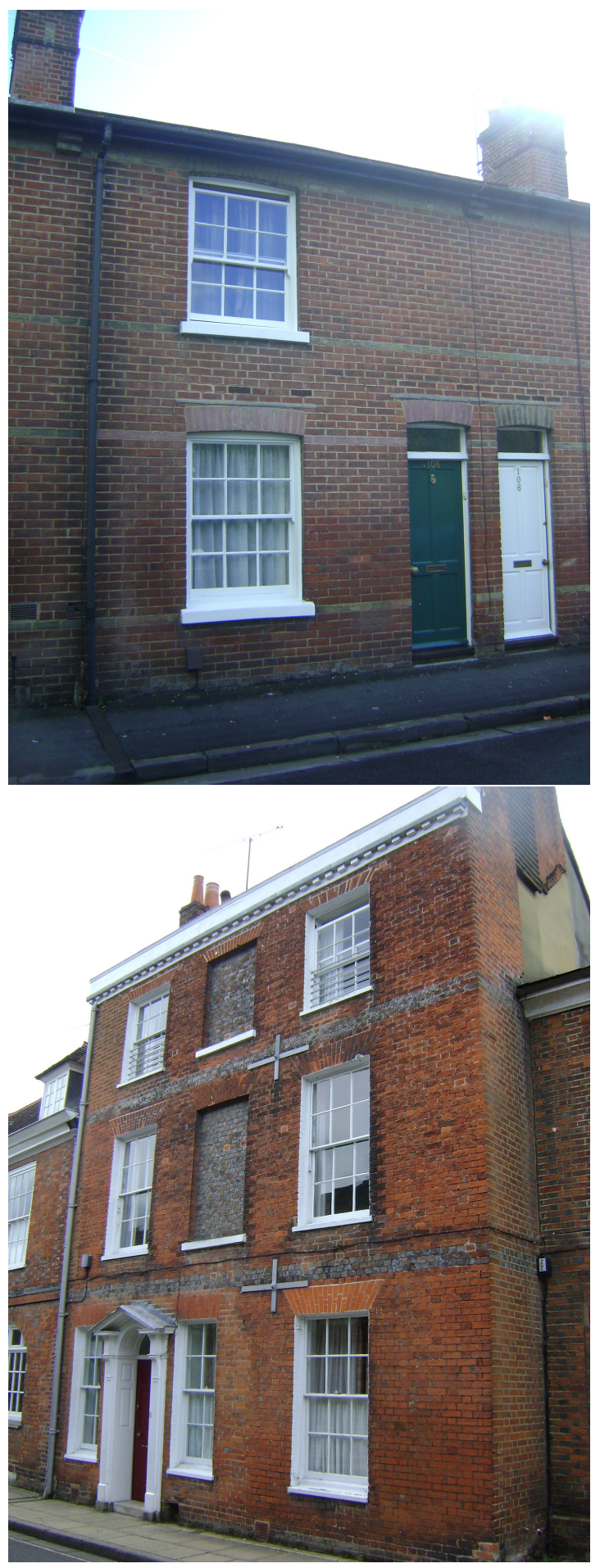

Fig. 7. (a) Water Lane, Winchester, (b) Kingsgate Street, Winchester.

The next stage in the process is to develop the descriptor responses into a more quantitative form than at the current time, which will provide the basis for more detailed probabilistic damage assessment. Quantitative indicators of 

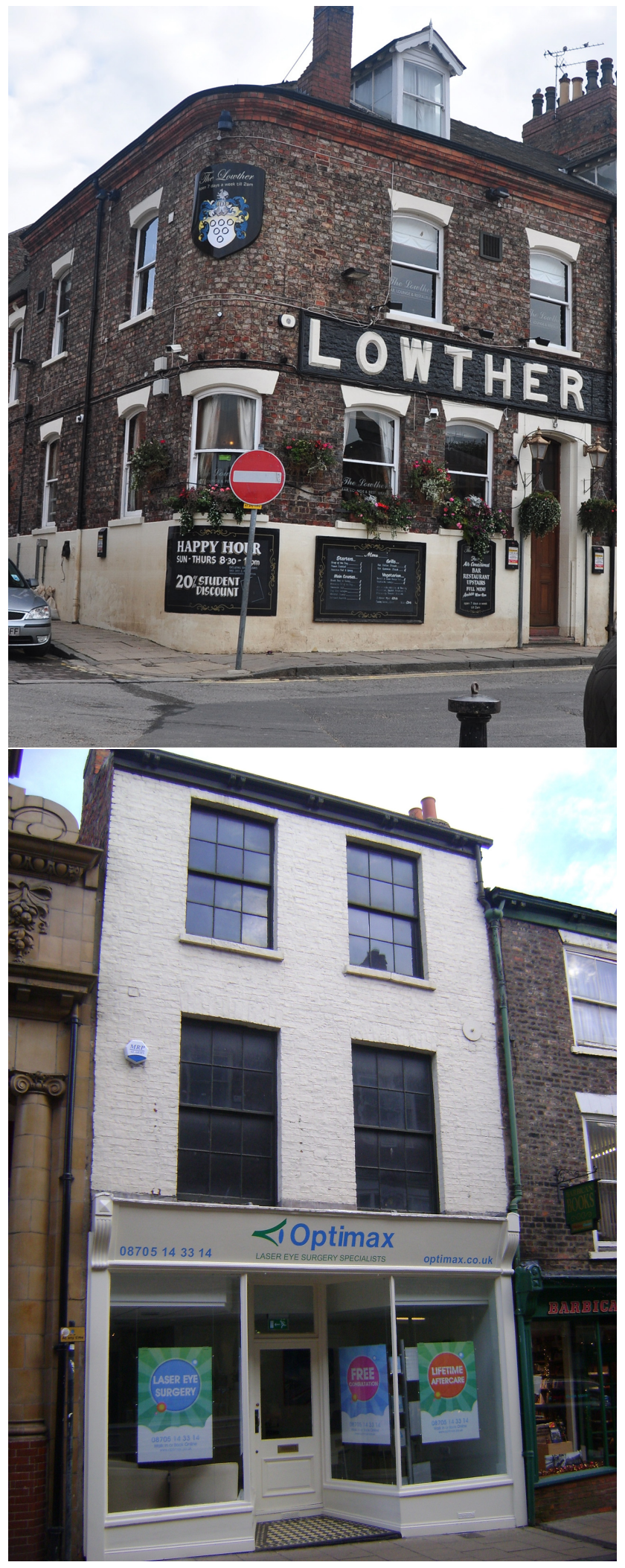

Fig. 8. (a) Riverfront, York, (b) Fishergate, York.
Table 4. York vulnerability index comparison.

\begin{tabular}{ll}
\hline Riverfront, York & \\
\hline Not listed & 10 \\
3 storeys & 70 \\
Brick masonry & 40 \\
Georgian & 55 \\
Excellent condition & 10 \\
Vulnerability index & $185 / 500$ \\
\hline Fishergate, York & \\
\hline Grade II & 40 \\
3 storeys & 70 \\
Brick masonry & 40 \\
Georgian & 55 \\
Poor condition & 100 \\
Vulnerability index & $305 / 500$ \\
\hline
\end{tabular}

Case 3: brick masonry commercial buildings in York.

vulnerability would also further enhance the application of this assessment to fragility analysis. Examples such as the area of apertures as a proportion of total exposed wall area, and the ratio of wall thickness to storey height, would add important detail to the material and structure parameter, as would more detail about the nature of the wall materials, such as stone type and associated porosity characteristics. Collection of such information requires a more lengthy and intrusive survey method than this first attempt allowed for, but work in this direction that will inform the setting out of guidance documents in the field of preservation of heritage exposed to flooding is envisaged as part of second screening.

\section{Vulnerability index: the basis of future risk assessment}

One key aim of this methodology is to provide a simple and hence widely applicable means of holistically assessing the vulnerability of a heritage building, so that it can be considered appropriately in the wider scheme of urban flood risk estimation. Therefore the approach has been to combine the responses for each parameter by building to give a single measure of vulnerability, the vulnerability index (VI). This is the value obtained from summating each VR for the parameters contributing to vulnerability to give a total ranging between 50 and 500, as shown for each of the exemplar buildings in Tables 2, 3 and 4 .

Calculating the VI for each of the buildings on the site gives an indication of overall trends in site vulnerability, which can be used to compare sites at risk. Figure 9 shows the cumulative log-normal distribution of vulnerability index values for the three sites surveyed, with the $x$ axis indicating the upper and lower limits of possible VI values. The distribution highlights clearly that the surveyed stock at 


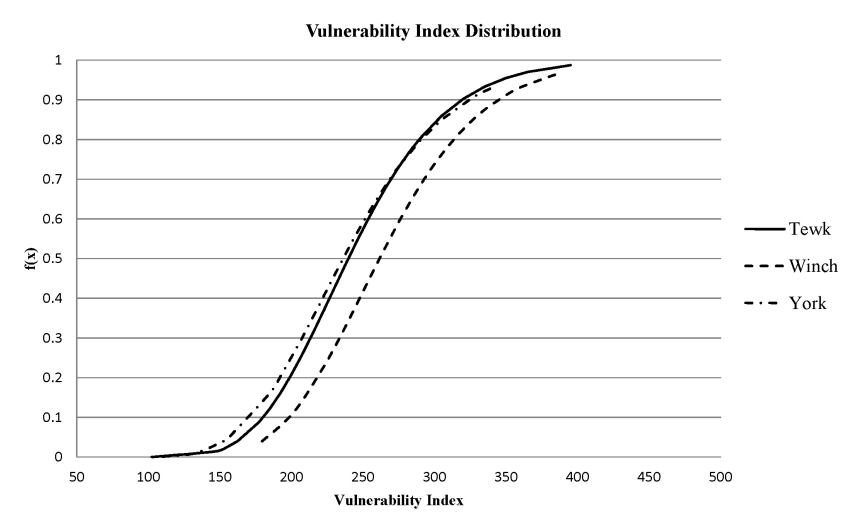

Fig. 9. Vulnerability index distribution.

Winchester is more vulnerable than at both York and Tewkesbury, and with all the samples being slightly skewed towards the lower boundary.

Furthermore, more detailed assessment of the risk is achieved by analysing the vulnerability ratings in conjunction with the flood hazard through GIS mapping. This profiles the distribution of vulnerability geographically across the site, aligning it with the hazard posed by flood depth and extent. Figure 10 shows the VI value for each surveyed building on the site of Tewkesbury, classified into four categories of increasing vulnerability state. Buildings with less than $25 \%$ of the total vulnerability index are classified as low vulnerability, and each incremental $25 \%$ step equates to a higher classification.

As can be seen, the use of this vulnerability indicator system, which is independent of the hazard, highlights building vulnerability prior to flood inundation, and therefore has a scattered distribution across the site. In order to develop the method into an assessment of risk, a separate measure of the exposure of each building to the flood hazard is needed. This requires detailed measurement of the flood parameters at the scale of the individual building, which is little documented and requires original work to be done for each individual site.

\section{Conclusions}

This paper presents a novel methodology by which the vulnerability of built cultural heritage can be recorded, appraised and quantified. The method relates specifically to flood events and the associated decay and damage potential, and is drawn from a specific definition of vulnerability that it is believed is most applicable to historic buildings. The method presented here is the first stage in the development of a clearly defined strategy for appraising flood risk to historic structures, and developing specific damage functions.

The development of a novel approach to vulnerability assessment considers both the exposed buildings and the hazardous flood through a series of risk indicators specific to the intrinsic properties that contribute to the value of the asset, and the damage phenomena observed after such natural disasters occur. The holistic approach to the problem has proved to be successful in demonstrating the potential for fragility analysis in relation to this relatively newly identified environmental hazard to historic buildings. Furthermore, it has enabled the focussing of future work upon key conflicting philosophical arguments that influence the methodology, which stem from the wide variety of considerations that contribute to the managed protection of cultural heritage.

The application to three case study sites for a total of six hundred buildings has shown that the procedure is capable of identifying both individual building and site-wide vulnerability, showing the vulnerability indicators to be independent and exhaustive in characterising the fragility of each unit of assessment. Study of further sites will allow for improvement of the detail in the method, leading to the production of a national framework for risk assessment specifically related to the problem of flooding of historic urban centres.

As there is no model against which to calibrate our sample, due to the lack of previous anecdotal studies, it is difficult to calculate any uncertainty, other than epistemic uncertainty associated with differing experience and knowledge amongst the surveyors. In this respect condition is the parameter open to the greatest uncertainty. As a test two surveyor responses for the sample in Tewkesbury were compared to determine the degree of disparity (Fig. 11). It is shown that Surveyor 1 tended to consider buildings in better condition than Surveyor 2, skewing their results in this direction. Even this simple investigation raises important questions concerning the assessment of historic buildings, supporting the call for standardised measures of building condition to be incorporated into any future iterations of the work.

Uncertainty associated with further effects of subjectivity within the parameters has been discussed previously in the paper, although the cumulative effect of this will form the core analysis of future use of the method. Application of the method in Europe would allow for further iteration using a larger, more diverse data sample, and would provide valuable work to reduce uncertainty associated with these issues. Application at this geographical scale is feasible, providing that where appropriate the parameters are adjusted to account for local conditions, such as national forms of recognising heritage, similar to the UK's listing system, and also that surveyors with strong knowledge of local heritage and hazard factors are used.

The work clearly sets out future directions of work, such as focus on the development of the method to incorporate weighting of the vulnerability ratings with a rationale appropriate to the conservation principles. The next stage of the work, development of a risk index applicable at the individual building scale, which incorporates both building vulnerability and flood hazard, is underway and will be presented in a future paper. From the vulnerability index fragility curves can be derived at the scale of individual building typology 


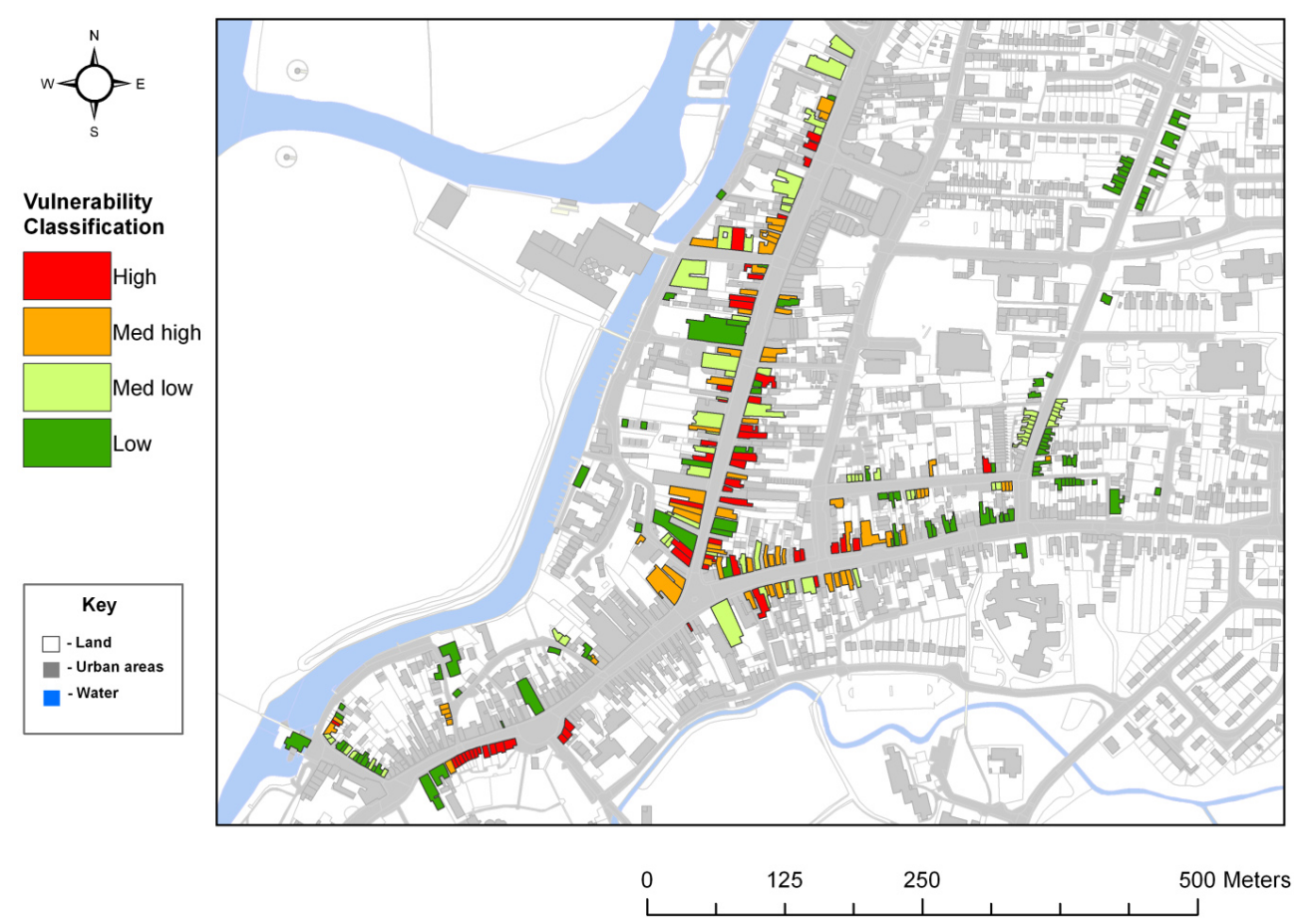

Fig. 10. Vulnerability classification map of Tewkesbury.

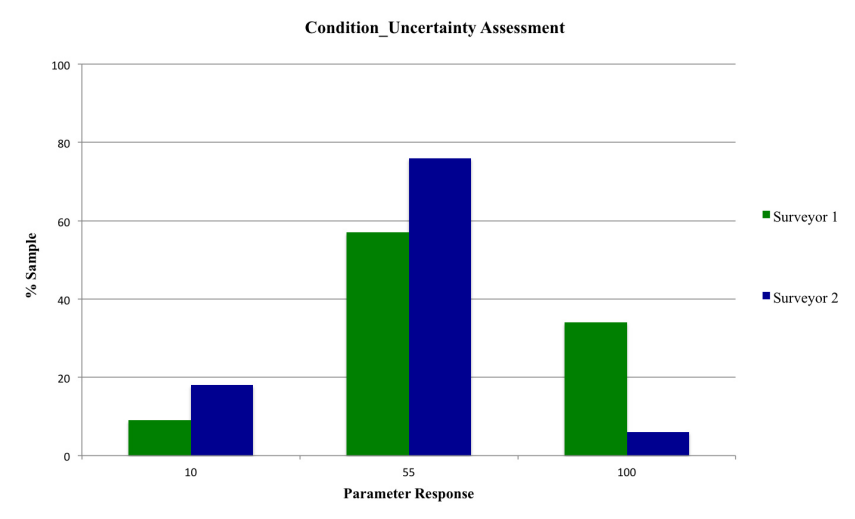

Fig. 11. Comparison of survey responses for conditions, to determine uncertainty within Tewkesbury.

and at site scale as shown in Sect. 5. Convolving the present results with flood depth levels will represent the first attempt at producing depth-damage curves specifically for historic structures exposed to flood hazards.
Acknowledgements. The authors wish to acknowledge the use of publicly available data provided by the British Atmospheric Data Centre, the UK Meteorological Office and the Ordnance Survey Collection. Collection of data through this survey was facilitated by the support of residents and local authorities from the communities of the sites surveyed. The authors wish to gratefully acknowledge the contribution of all research students and research associates from the Parnassus project during the survey phase of the work.

Edited by: P. Bubeck

Reviewed by: four anonymous referees

\section{References}

Baker, P. H., Sanders, C., Galbraith, G. H., and McLean, R. C.: Investigation of Wetting and Drying Behaviour of Replica Historic Wall Constructions, Engineering Historic Futures, UCL, London, 2007.

Cassar, M.: Climate Change and the Historic Environment, The Russell Press, Nottingham, 2005.

CHEF: Cultural Heritage Protection against Flooding, edited by: Drdacky, M., Binda, L., Hennen, C., Kopp, C., Lanza, L., and Helmerich, R., ITAM, Prague, 2011.

D'Ayala, D.: Force and displacement based vulnerability assessment for traditional buildings, B. Earthq. Eng., 3, 235-265, 2005

D'Ayala, D., Copping, A., and Wang, H.: A conceptual model for multi-hazard assessment of the vulnerability of historic buildings, in: Structural Analysis of Historical Constructions: Possibilities of Numerical and Experimental Techniques, Proceedings of the Fifth International Conference, New Delhi, India, 
2006, edited by: Lourenco, P. B., Roca, P., Modena, C., and Agrawal, S., MacMillan, 1, 121-140, 2006.

DCMS: Principles for Selection of Listing Buildings, Department for Culture, Media and Sport, UK Government, London, UK, 2010.

DEFRA (Department for the Environment, Food and Rural Affairs): The national flood and coastal erosion risk management strategy for England, UK, available at: http://www.environment-agency. gov.uk/research/policy/130073.aspx, last access date: 18 July 2013, 2011.

Drdacky, M.: Flood damage to historic buildings and structures, J. Perform. Constr. Fac., 24, 439-445, 2010.

Elmer, F., Thieken, A. H., Pech, I., and Kreibich, H.: Influence of flood frequency on residential building losses, Nat. Hazards Earth Syst. Sci., 10, 2145-2159, doi:10.5194/nhess-10-21452010, 2010.

English Heritage: Flooding and Historic Buildings, Technical Advice Note, English Heritage Publishing, Swindon, UK, 2004.

English Heritage: Listing Historic Buildings, available at: http:// www.english-heritage.org.uk/caring/listing/listed-buildings (last access: 12 June 2012), 2012.

EA (Environment Agency): Flood Map Database, available at: , last access: 26 November 2010.

Evans, E., Hall, J. E., Penning-Rowsell, P., Sayers, C. and Thorne, A.: Watkinson Proceedings of the ICE - Water Management, 159, 53-61, 2006.

FEH (Flood Estimation Handbook), Centre for Ecology and Hydrology, Wallingford, UK, 1999.

Genovese, E. A.: methodological approach to land use-based flood damage assessment in urban areas: Prague case study, EUR22497 EN, 2006, European Commission, Ispra, Italy.

HAZUS, Department for Homeland Securty, Federal Emergency Management Agency, Mitigation Division: Multi-Hazard Loss Estimation Methodology, Flood Model HAZUS MH MR4, Technical Manual, 2009.

Hannaford, J.: UK Flooding - Briefing from the Centre for Ecology and Hydrology - 20 November 2009, available at: http://www. ceh.ac.uk/news/news_archive/2009_news_item_48.html, last access: 7 March 2012, 2009.

Holicky, M. and Sykora, M.: Risk assessment of heritage structures endangered by fluvial floods, WIT Transactions on Ecology and the Environment, Vol. 133, WIT Press, Southampton, UK, 2010a.

Holicky, M. and Sykora, M.: Assessment of flooding risk to cultural heritage in historic sites, J. Perform. Constr. Fac., 24, 439-445, 2010b.

Jongman, B., Kreibich, H., Apel, H., Barredo, J. I., Bates, P. D., Feyen, L., Gericke, A., Neal, J., Aerts, J. C. J. H., and Ward, P. J.: Comparative flood damage model assessment: towards a European approach, Nat. Hazards Earth Syst. Sci., 12, 3733-3752, doi:10.5194/nhess-12-3733-2012, 2012.

Kelman, I.: Physical Vulnerability of Residential Properties in Coastal, Eastern England, Ph.D. thesis, University of Cambridge, UK, 2002.

Kelman, I. and Spence, R.: A limit analysis of unreinforced masonry failing under flood water pressures, Masonry International, 16, 51-61, 2003.

Kelman, I. and Spence, R.: An overview of flood actions on buildings, Eng. Geol., 73, 297-309, 2004.
Kreibich, H., Piroth, K., Seifert, I., Maiwald, H., Kunert, U., Schwarz, J., Merz, B., and Thieken, A. H.: Is flow velocity a significant parameter in flood damage modelling?, Nat. Hazards Earth Syst. Sci., 9, 1679-1692, doi:10.5194/nhess-9-1679-2009, 2009.

MAFF: Strategy for flood and coastal defence in England and Wales Ministry of Agriculture, Fisheries and Food, London, UK, MAFF, 1993.

MacDonald, N.: Trends in flood seasonality of the River Ouse (Northern England) from archive and instrumental sources since AD 1600, Climatic Change, 110, 901-923, 2012.

Maiwald, H. and Schwarz, J.: Damage and loss prediction model considering inundation level, flow velocity and vulnerability of building types. Flood Recovery, Inundation and Response III. WIT Transactions on Ecology and the Environment, Vol. 159. WIT Press, 2012

Marsh, T. J. and Hannaford, J.: The summer 2007 floods in England and Wales - a hydrological appraisal, Centre for Ecology and Hydrology, Oxfordshire, UK, 2007.

Mebarki, A., Valencia, N., Salagnac, J. L., and Barroca, B.: Flood hazards and masonry constructions: a probabilistic framework for damage, risk and resilience at urban scale, Nat. Hazards Earth Syst. Sci., 12, 1799-1809, doi:10.5194/nhess-12-17992012, 2012.

Messner, F., Penning-Rowsell, E., Green, C., Meyer, V., Tunstall, S., and van der Veen, A.: Evaluating flood damages: guidance and recommendations on principles and methods, FLOODsite Project Deliverable D9.1, Contract No: GOCE-CT-2004-505420, available at: , last access: 12 June 2012, 2006.

Merz, B., Kreibich, H., Schwarze, R., and Thieken, A.: Review article "Assessment of economic flood damage", Nat. Hazards Earth Syst. Sci., 10, 1697-1724, doi:10.5194/nhess-10-16972010, 2010a.

Merz, B., Hall, J., Disse, M., and Schumann, A.: Fluvial flood risk management in a changing world, Nat. Hazards Earth Syst. Sci., 10, 509-527, doi:10.5194/nhess-10-509-2010, 2010 b.

Met Office: Met Office News Blog, available at: http://metofficenews.wordpress.com/2012/06/23/

heavy-rainfall-across-parts-of-the-uk (last access: 25 June 2012), 2012.

Nadal, N. C., Zapata, R. E., Pagan, I., Lopez, R., and Agudelo, J. Building damage due to riverine and coastal floods, J. Water Res. Pl.-ASCE, 136, 327-336, 2010.

NERC: The 2000/01 Floods - a Hydrological Appraisal, available at: http://www.nerc-wallingford.ac.uk/ih/nrfa/yb/yb2000/ flood2000/2000FloodIndex.html, last access: 18 February 2012, 2000.

NERC: Hydrological Summary for the UK, July 2007, CEH Wallingford, Oxfordshire, UK, 2007.

NOAHS ARK: Noah's Ark Project Consortium Website, available at: http://noahsark.isac.cnr.it/stateofart.php?html_contents= ./contents/stateofart/structures.html, last access: 11 August 2012, 2004.

Osborn, T. and Maraun, D.: Changing Intensity of Rainfall over Britain, Climatic Research Unit Information Sheet No. 15, Norwich, UK, 2008.

Penning-Rowsell, E., Johnson, C., Tunstall, S., Tapsell, S., Morris, J., Chatterton, J., and Green, C.: The Benefits of Flood 
and Coastal Risk Management: A Manual of Assessment Techniques, Middlesex Univ. Press, Oxfordshire, UK, 2005.

Petrow, T., Theiken, A. H., Kreibich, H., Bahlburg, C. H., and Merz, B.: Improvements on Flood Alleviation in Germany: Lessons Learned from the Elbe Flood in August 2002, Environ. Manae., 38, 717-732, doi:10.1007/s00267-005-6291-4, 2006.

Sabbioni, C., Cassar, M., Brimblecombe, P., Tidblad, J., Kozlowski, R., Drdacky, M., Saiz-Jiminez, C., Grontoft, T., Wainwright, I., and Arino, X.: Global climate change impact on built cultural heritage and cultural landscapes, in: Heritage Weathering and Assessment, edited by: Fort, R., Alvarez de Buergo, M., Gomez-Heras, M., and Vazquez-Calvo, C., Taylor and Francis/Balkema, Madrid, Spain, 395-401, 2006.

Schwarz, J. and Maiwald, H.: Damage and Loss Prediction Model Based on the Vulnerability of Building Types, 4th International Symposium on Flood Defence, Managing Flood Risk, Reliability and Vulnerability, Toronto, Ontario, Canada, 6-8 May 2008.
Smith, K. and Ward, R.: Floods: physical processes and human impacts, John Wiley, Chichester, UK, 1998.

Stephenson, V. and D'Ayala, D.: A novel laboratory procedure to investigate the effect of flooding on historic structures., 2nd European Workshop on Cultural Heritage Preservation, Oslo, Norway, 24-26 September 2012.

Thieken, A. H., Muller, M., Kreibich, H., and Merz, B.: Flood damage and influencing factors: new insights from the $\mathrm{Au}$ gust 2002 flood in Germany, Water Resour. Res., 41, W12430, doi:10.1029/2005WR004177, 2005.

York Press: available at: last access: 8 December 2012.

Ulbrich U., Brucher, T., Fink, A. H., Leckebusch, G. C., Kruger, A., and Pinton, J. G.: The central European floods of August 2002: Part 1 - Rainfall periods and flood development, Weather, 58, 371-377, doi:10.1256/wea.61.03A, 2008.

USACE: Business Depth-damage Analysis Procedures, US Army Corps of Engineers, Institute of Water Resources, 1985. 